\title{
Project based learning: Effective tool for a course on Electronic Product Design
}

\author{
Ms. Lekha Das ${ }^{1}$, Ms. Amita Naiksatam ${ }^{2}$ Ms. Megha Shama ${ }^{3}$ \\ ${ }^{1}$ Department of Electronics, K.J.Somaiya College of Engineering, Vidyavihar, Mumbai-400077, India. \\ ${ }^{2}$ Department of Electronics, K.J.Somaiya College of Engineering, Vidyavihar, Mumbai-400077, India. \\ ${ }^{3}$ Department of Electronics, K.J.Somaiya College of Engineering, Vidyavihar, Mumbai-400077, India. \\ ${ }^{1}$ lekhadas@somaiya.edu , \\ 2aynaiksatam@somaiya.edu, \\ 33eghashama@somaiya.edu
}

Abstract: The paper discusses an efficient way of implementing Project based learning (PBL) for an engineering course on Electronic Product Design. The course objective is to bridge the gap between a research idea to a product. The active learning pedagogy carried out helps in achieving the higher order educational objectives in Bloom's taxonomy like analysis, synthesis, evaluation etc. The adopted method also puts forth a point that in some courses summative assessment may not always be the right yard stick.

Keywords: Experiential learning, Project based learning (PBL), Electronic Product Design, active learning pedagogy, MOODLE, Bloom's Taxonomy.

\section{Introduction}

The product design course was designed to understand and explore the design techniques adopted for any product. The course goes through complete stages of electronic product design. Through the course we intended to enhance critical thinking skills, understand diverse topics of product and industrial design, along with exposure to tools and techniques to translate their vision into product. But, with this aim, as a teacher it was a challenging assignment for us to make learners attend the theory lecture of illustrating different stages of product development. So learning through doing, was another option which we used successfully in other courses and decided to do so in this course as well.

For this course we opted project based learning. Twenty students were registered for the course. They were divided into teams of two members. Two assignments were allotted to each team. The assignments were uploaded through MOODLE, an open source ICT tool.MOODLE (Modular Object-Oriented Dynamic Learning Environment) is a platform for education which provides custom learning environment for students Moodle is a webbased Learning Management System (LMS). Documents can be shared and accessed in an arranged order. Online assignments save time and make submission procedure simple. Following activities were assigned to students as a part of internal assessment tool.

- To mimic an existing product. This helped the students to explore the aesthetics and ergonomics of the product. This activity was designed for analyzing and developing the creative minds of students.

- To develop a product applying all stages of product design.The details are explained in the methodology.

\section{Methodology}

As mentioned in the introduction the product design activity was carried as it is a proven fact that "learning by doing" is an effective way of achieving higher order Bloom's Taxonomy such as applying, analyzing, evaluating, creating. Steps followed for product design are:

1. Identification of customer requirements: For developing a product the foremost step is to do a survey among the customers to know their need. Moreover, the feasibility of transferring the needs to technical specifications has to be verified. The students were encouraged to do so and submit the survey and the analysis performed as a part of the assignment.

2. Designing and developing the product: Specifications were finalised using customer needs. Depending on specifications, designing of circuit on paper was completed.The circuit was tested using simulation tools. A prelimin Front panel control, packaging enclosures were designed. Prototype was prepared and tested for functionality.

3. Printed Circuit Board (PCB) design: After the prototype is tested, the role of PCB design is to mechanically support and electrically connect the components through conductive paths. Design requirements include mechanical, electrical, functional and environmental design requirements. 
4. Hardware testing and software testing: Various hardware tools and software tools were explored for testing. Troubleshooting and debugging was done and faults were eliminated.

5. Importance of standards: A standard is an established norm of a product, to establish a uniform engineering or technical criteria, specifications, processes, and practice regarding the products. The main purpose of standards in the promotion of optimum community benefits and approved by a committee recognised by a regional, national, and international level. So, the students were informed to follow some standard while designing the product.

6. Product Documentation: For any product development documentation is inevitable. The document includes proposal, engineering diary, drawings and schematics, software documentation, brochures, presentation documents, manual, memos, and electronic files. The students submitted user manual and product report as a part of continuous assessment along with the product.

The above discussed procedural steps were implemented as follows:

Students uploaded the product documentation along with user manual on the MOODLE classroom.
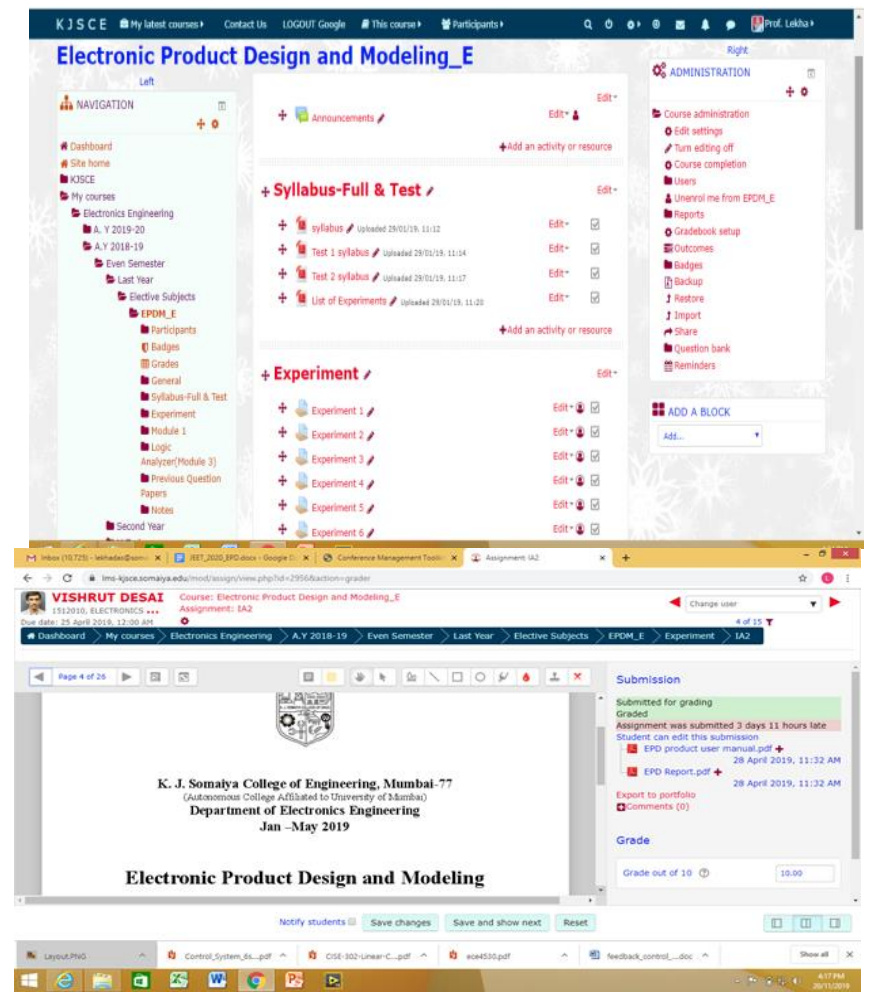

FIGURE: 1 SAMPLE OF ASSIGNMENT UPLOADED ON MOODLE CLASSROOM

\section{Results and discussion Page Style}

The few look-alike products submitted by students are shown:

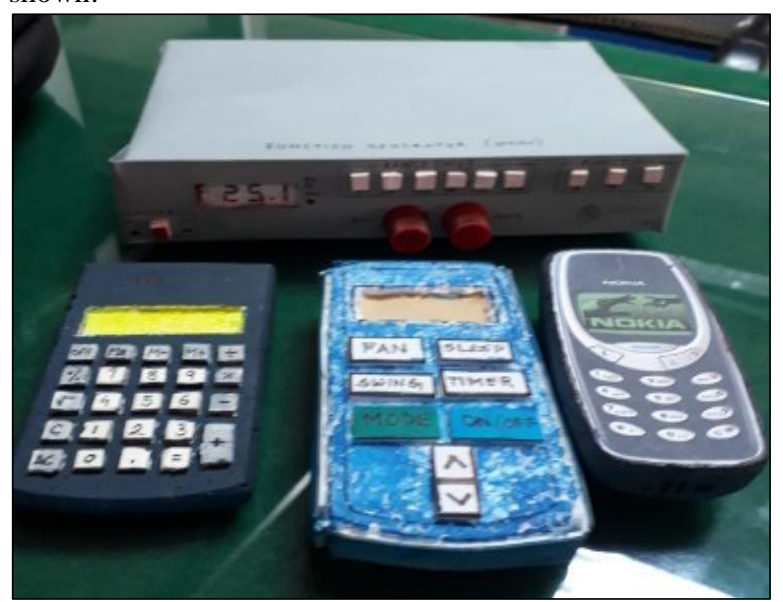

FIGURE:2 PRODUCT MODEL

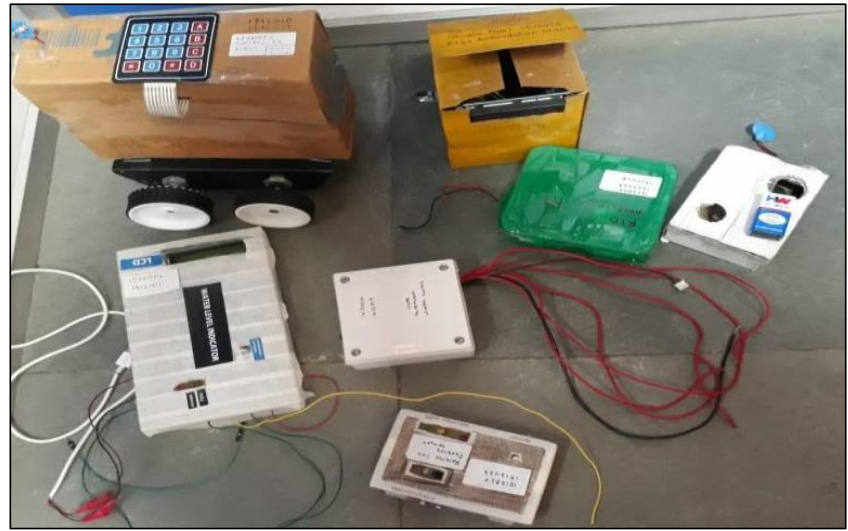

FIGURE:3 WORKING MODEL

After the completion of the course, students' feedback was taken through moodle. It was done to know how well they have understood the concepts of the course. These act as an indirect method to quantify the course outcomes. The feedback would be useful while redesigning the curriculum. The students' comments on preferable mode of conduction were also collected.

Have you understood the different steps involved in product design? 12 responses

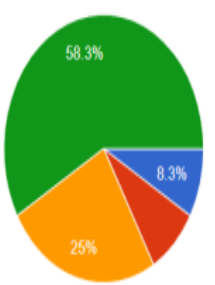

1
-12
3

-

FIGURE:4 STUDENTS' RESPONSE 
Can you design PCB and assemble components while making a product?
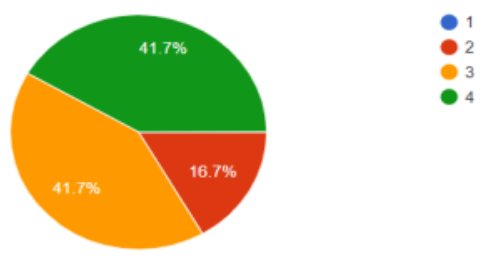

FIGURE:5 STUDENTS’ RESPONSE

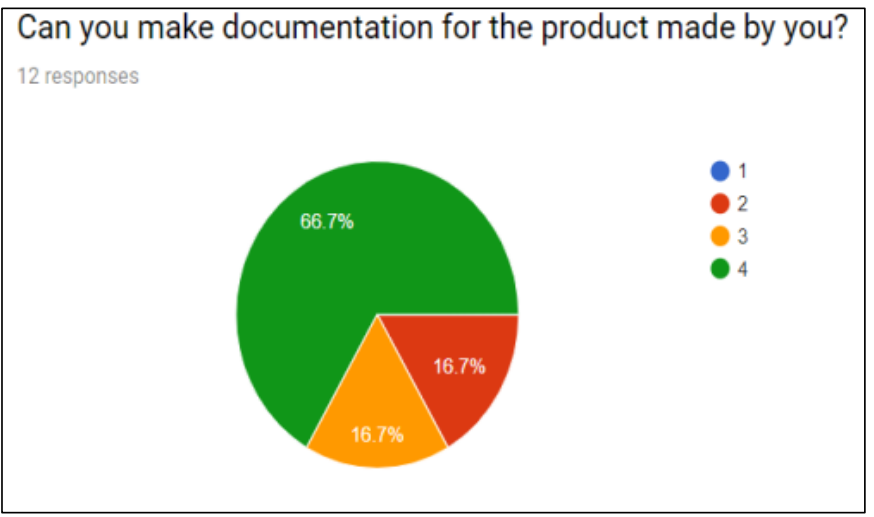

FIGURE:6 STUDENTS'RESPONSE

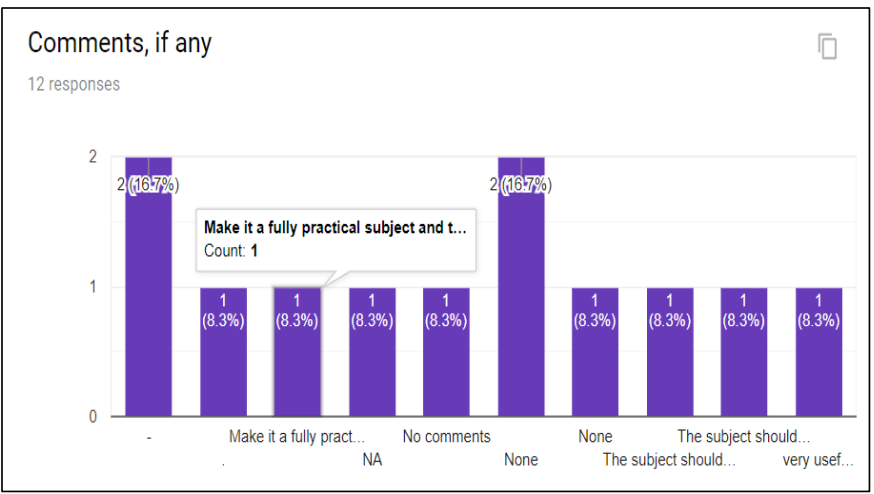

FIGURE:7 STUDENTS' COMMENTS

\section{Conclusions}

Since, the course deals with the flow of Electronic product design; we feel that the continuous assessment through the above discussed methodology is more valid than the end semester evaluation. The final product submitted by the student and from the procedural submission of different activities it can be concluded that the course was better understood by them. All assignments were uploaded and graded through MOODLE classroom, and will be available for any future reference. The project based learning that was adopted ensured engagement of the students through the course. The active learning course helped the students to understand the course in a better manner. This surely enhanced the attainment of course outcomes.

\section{References}

[1] Dr. Aruna Shekar, A. B. Author, Project based Learning in Engineering Design Education: Sharing Best Practices, 121st ASEE Annual conference and exploration, June 15-18, 2014.

[2 ]Ignacio de losRíosAdolfoCazorlaJosé M.DíazPuenteJosé L.Yagüe, Project-based learning in engineering higher education: two decades of teaching competences in real environments, Procedia - Social and Behavioral Sciences Volume 2, Issue 2, 2010,Pages 1368-1378.

[3] Simone Borges Simão Monteiro,Ana Carla Bittencourt, Reisa,João Mello da Silvaa ,João Carlos Felix SouzA Project-based Learning curricular approach in a Production Engineering Program. 